\title{
Knowledge, Attitude and Practice on Use of Laser in Disinfection of Canals
}

\author{
Harini Kumaran ${ }^{1}$ and Manish Ranjan² \\ ${ }^{1}$ Saveetha Dental College and Hospitals, Saveetha Institute of Medical \\ and Technical Sciences, Saveetha University, Chennai, India. \\ ${ }^{2}$ Reader Department of Conservative Dentistry and Endodontics Saveetha Dental College and Hospitals \\ Saveetha Institute of Medical and Technical Sciences Saveetha University Chennai 77, India
}

\section{ABSTRACT}

In the present era, Clinicians are keeny searching for better techniques, instruments and materials that enable the patient with better patient comfort and also superior dental treatment.The use of Laser enables the dentist to work more efficiently and precisely. Treatment of root canal leads to preservation of natural teeth that aid in mastication and esthetics.The more recent development in endodontic treatment is the use of laser. The study aims to assess and to create awareness on knowledge,attitude and practice on use of lasers in disinfection of canals.The study had a sample size/respondents of 100 dental students. An online survey with a pretested and validated questionnaire consisting of 11 questions testing awareness of laser use in disinfection of canals. The Questions regarding laser advantages,limitations, mode of action, wavelength used in disinfection of the canal were framed and shared with 100 dental students and their answers were recorded. Data was entered in Microsoft Excel sheets. The results were demonstrated in the form of pie charts. Association between gender and students awareness on different variables were assessed using chi square test.From the present study, we can conclude that female participants are more aware on laser effect, laser advantages, limitations and on adjuvant role of laser with irrigants, wavelength of Er:YAG,Er,Cr:YSGG, Diode, carbon dioxide laser in disinfection of canals and males are more aware of the wavelength of Nd:YAG. But there is a need for an awareness among students regarding the current application of LASER for providing better treatment without any complications.

KEY WORDS: DIODE; DISINFECTION; LASER; ROOT CANAL.

\section{INTRODUCTION}

Preservation of teeth by endodontic therapy has gained a lot of popularity because of the increased and predictable success rate. The main purpose of the root canal is to eradicate microorganisms which are responsible for

\section{ARTICLE INFORMATION}

*Corresponding Author: manish@saveetha.com Received 14th July 2020 Accepted after revision 27th Sep 2020 Print ISSN: 0974-6455 Online ISSN: 2321-4007 CODEN: BBRCBA

Thomson Reuters ISI Web of Science Clarivate Analytics USA and Crossref Indexed Journal

\section{Clarivate
Analytics}

NAAS Journal Score 2020 (4.31) SJIF: 2020 (7.728)

A Society of Science and Nature Publication,

Bhopal India 2020. All rights reserved.

Online Contents Available at: http//www.bbrc.in/

Doi: http://dx.doi.org/10.21786/bbrc/13.8/168 infection and prevention of its re-infection during and after treatment(Narayanan and Vaishnavi, 2010; Jain and Ranjan, 2014).Removal of microorganisms from the infected root canal is a complicated task(Sheik and Ranjan, no date). This can be achieved by chemomechanical debridement(Siddique et al., 2020). Standard Endodontic Irrigation Protocols includes Sodium Hypochlorite ( $\mathrm{NaOCl}$ )Ethylene-diamine-tetra-acetic Acid (EDTA)Chlorhexidine (CHX).In addition, there are other disinfection systems such as Photo-Activated Disinfection (PAD),LASER, OZONE(Plotino et al., 2016).Most currently used irrigants and intracanal medicaments has limited antibacterial activity and limited ability to diffuse into dentinal tubules.

Newer technologies like LASER can penetrate $>1000 \mu \mathrm{m}$ into dentin thus facilitating the complete canal

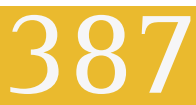


sterilization. LASER stands for light amplification by stimulated emission of radiation. The laser wavelengths described for cleaning and disinfecting the root canal system are: erbium: yttrium aluminium garnet (Er:YAG), $2940 \mathrm{~nm}$; erbium, chromium: yttrium scandium gallium garnet (Er,Cr:YSGG), $2780 \mathrm{~nm}$; neodymium:yttrium aluminium garnet (Nd:YAG), $1064 \mathrm{~nm}$; diode, 635 to $980 \mathrm{~nm}$; potassium titanyl phosphate (KTP), $532 \mathrm{~nm}$; carbon dioxide (CO2), 9600 and $10600 \mathrm{~nm}$.(Asnaashari and Safavi, 2013).Initially Nd: YAG laser was first used for root canal disinfection. It is introduced by Hardee and Myers and McDaniel. Moritz et al. introduced use of diode laser for root canal disinfection(Kaiwar et al., 2013).Laser has its own advantages such as penetration of secondary canals, improved disinfection efficacy, more effective root canal cleaning, reduction of permeability, reduction of micro-leakage, and elimination of the need to use toxic solvents(Gutknecht, 2008). Laser has its own disadvantages. The interaction between laser and tissue results in rise in temperature.

The rise in temperature results in damage to soft tissue. If the temperature is too high, it may result in injury to the surrounding bone.Since root canals are more curved than straight, root canal instruments can be curved following the curvature of the canal and clean the canal. But in contrast, Laser light travels in a straight path(Mathew et al., 2015). Even Though, laser has its own advantages and disadvantages, the clinicians acceptance towards laser technology still remains limited(Meire and De Moor, 2007).We have numerous highly cited publications on well designed clinical trials and lab studies(Govindaraju, Neelakantan and Gutmann, 2017; Azeem and Sureshbabu, 2018; Jenarthanan and Subbarao, 2018; Manohar and Sharma, 2018; Nandakumar and Nasim, 2018; Teja, Ramesh and Priya, 2018; Janani and Sandhya, 2019; Khandelwal and Palanivelu, 2019; Malli Sureshbabu et al., 2019; Poorni, Srinivasan and Nivedhitha, 2019; Rajakeerthi and Ms, 2019; Rajendran et al., 2019; Ramarao and Sathyanarayanan, 2019; Siddique and Nivedhitha, 2019; Siddique et al., 2019; Siddique, Nivedhitha and Jacob, 2019). This has provided the right platforms for us to pursue the current study. This vast research experience has inspired us to research about the awareness of use of lasers in disinfection of canals among dental students.

\section{MATERIAL AND METHODS}

The study was conducted in a private dental institution in Chennai. The study setting was carried out in a University setting with approval of the Institutional review board. Inclusion criteria and Exclusion criteria. Undergraduate third year students, final year students and Interns were included in the study. Post graduate students and dental practitioners were excluded from the study.

Data Collection: A pre-tested questionnaire with 11 questions was formulated for the collection of information. The questionnaire was simple and brief. The self made questions were developed. The questionnaire included self made questions to assess about the knowledge, practise and awareness among the dental students regarding use of laser in disinfection of canals. The questionnaire was shared with 100 dental students and practitioners and their answers were recorded using an online surveying tool( Google Forms).

Statistical Analysis: Data was entered in Microsoft Excel sheets. The data was imported and transferred to the computer and subjected to statistical analysis using SPSS(IBM SPSS Statistics, Version 24.0, Armonk, NY: IBM Corp]. Chi-square test was performed to find the association between the variables. The level for a statistical significance was set at $p<0.05$. The results were demonstrated in the form of bar graphs.

\section{Questionnaire}

1.Are you aware that lasers are used in disinfection of root canal?

a)aware

b)not aware

2.In disinfection of root canals, Laser can be used as a)adjuvant with disinfectants

b)substitute to disinfectants

3)Action of laser in disinfection of canals

a)bactericidal

b)bacteriostatic

4)Type of laser used in disinfection of canals

a)Nd:YAG

b)Er:YAG

c)Er,Cr:YSGG

d)Diode

e)Carbon dioxide

f)all

5.Wavelegth of Nd:YAG laser used in disinfection of canals

a) $1064 \mathrm{~nm}$

b) $2780 \mathrm{~nm}$

c) $2940 \mathrm{~nm}$

d)635-980nm

e) $9600-10600 \mathrm{~nm}$

6.Wavelegth of Er:YAG laser used in disinfection of canals

a) $1064 \mathrm{~nm}$

b) $2780 \mathrm{~nm}$

c) $2940 \mathrm{~nm}$

d)635-980nm

e)9600-10600nm

7.Wavelegth of Er,Cr:YSGG laser used in disinfection of canals

a) $1064 \mathrm{~nm}$

b)2780nm

c) $2940 \mathrm{~nm}$

d)635-980nm

e) $9600-10600 \mathrm{~nm}$

8. Wavelegth of diode laser used in disinfection of 
canals

a) $1064 \mathrm{~nm}$

b) $2780 \mathrm{~nm}$

c) $2940 \mathrm{~nm}$

d)635-980nm

e)9600-10600nm

9.Wavelegth of Carbon dioxide laser used in disinfection of canals

a) $1064 \mathrm{~nm}$

b) $2780 \mathrm{~nm}$

c) $2940 \mathrm{~nm}$

d)635-980nm

e) $9600-10600 \mathrm{~nm}$

10.What are advantages of laser in disinfection of canals over conventional techniques

a)improved disinfection efficacy

b)more efficient root canal cleaning

c)reduction of permeability

d)reduction of microleakage

e)elimination of the need to use toxic solvents

f)all the above

11.What are the limitations of laser in disinfection of canals

a)thermal damage to periapical tissues

b)ledges

c)perforations

d)expensive

e)all the above

Figure 1: This graph shows the association between gender and number of respondents for the survey where $\mathrm{X}$-axis depicts the gender and Y-axis depicts the number of respondents. $p$ value- 0.834 ( $p>0.05$ ) which shows that it is not significant. However females $(40 \%)$ were more aware of laser use in disinfection of canals.

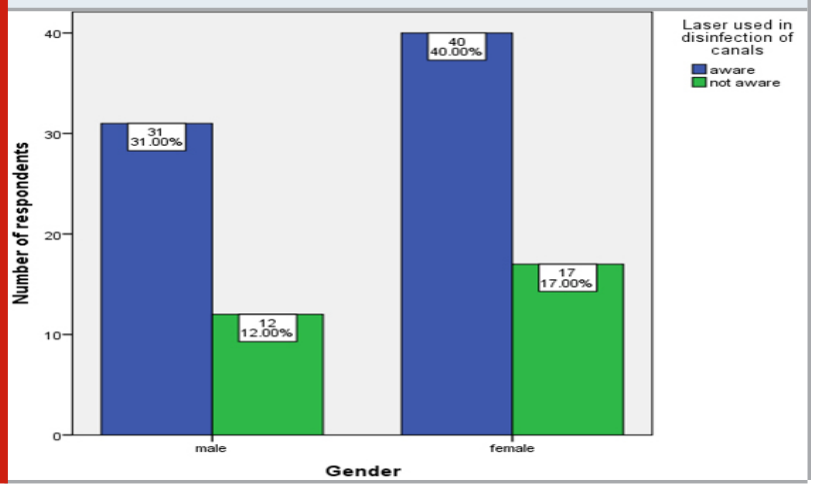

\section{RESULTS AND DISCUSSION}

43 male students and 53 female students participated in this study. From figure 1, it is evident that females $(40 \%)$ were more aware of laser use in disinfection of canals than males(31\%). From figure 2, it is evident that females(48\%)were more aware that lasers can be used only as adjuvant not as a substitute for irrigants than males(23\%). Ivano et al concluded no specific laser is superior to the traditional endodontic treatment. He also recommended laser cannot be used as an alternative to $\mathrm{NaOCl}$ but as an adjunct to the traditional disinfection and debridement methods(Juric and Anil, 2014).Several studies also proved better antibacterial effect when sodium hypochlorite is combined with laser(Kreisler et al., 2003; Perin et al., 2004).Mathew et al in his microbial study concluded use of diode laser or $\mathrm{NaOCl}$ alone did not produce considerable changes in bacterial colony. He also observed effective eradication of gram positive and aerobic bacteria when diode laser and $\mathrm{NaOCl}$ was used in combination(Mathew et al., 2015).

Figure 2: This graph shows the association between gender and number of respondents for the survey where $\mathrm{X}$-axis depicts the gender and $\mathrm{Y}$-axis depicts the number of respondents. $p$ value- $0.001(p<0.05)$ which shows that it is highly significant. It means females(48\%)were more aware that lasers can be used only as adjuvant not as a substitute for irrigants than males(23\%).

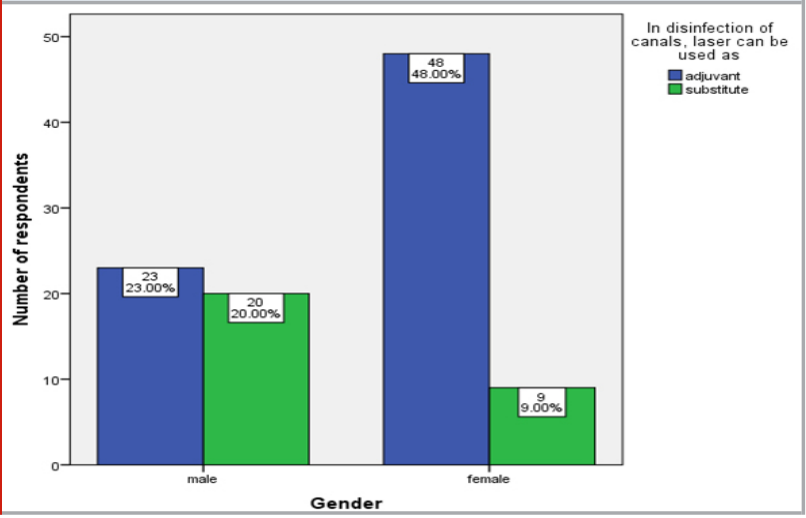

Figure 3: This graph shows the association between gender and number of respondents for the survey where $\mathrm{X}$-axis depicts the gender and $\mathrm{Y}$-axis depicts the number of respondents. $p$ value- 0.080 ( $p>0.05$ ) which shows that it is not significant. However females(39\%) were more aware that laser is bactericidal in action.

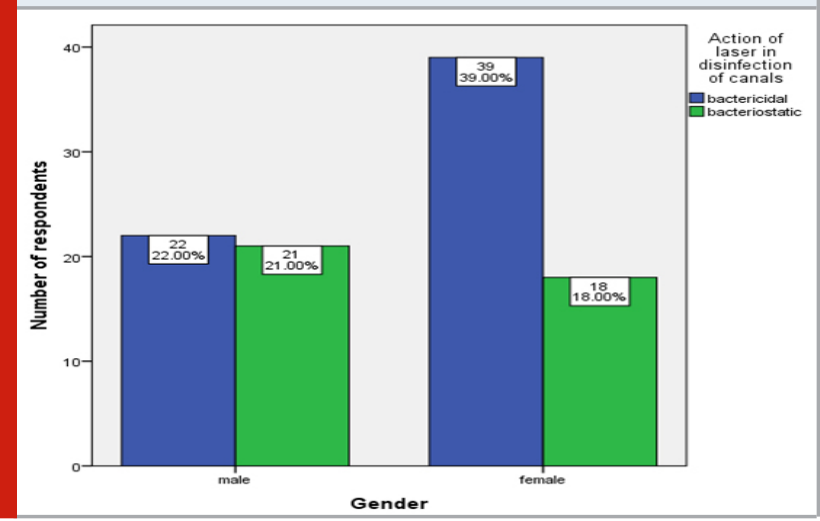

From figure 3, females(39\%) were more aware that laser is bactericidal in action than males(22\%). Diode laser has superior bactericidal effect than chemical disinfectants since the penetration of diode laser into dentinal tubules is upto $1000 \mu \mathrm{m}$ whereas in chemical disinfectants it is 
limited to $100 \mu \mathrm{m}$ (Preethee et al., 2012). Kaiwar et al also in his study concluded that $980 \mathrm{~nm}$ diodes can penetrate into dentin and eliminate bacteria which eventually increase the success rate of endodontic therapy(Kaiwar et al., 2013).

Figure 4: This graph shows the association between gender and number of respondents for the survey where $\mathrm{X}$-axis depicts the gender and Y-axis depicts the number of respondents. $p$ value- $0.103(p>0.05)$ which shows that it is not significant.However more females(18\%) were aware of the type of laser used in disinfection of canals.

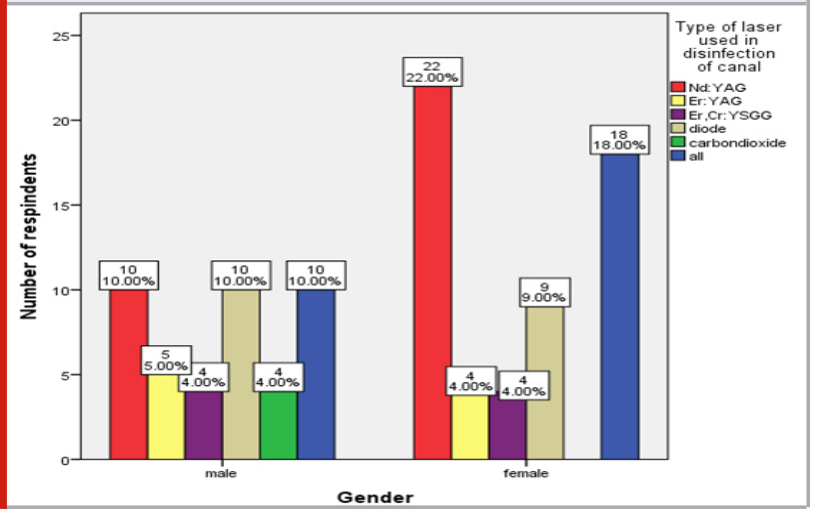

Figure 5: This graph shows the association between gender and number of respondents for the survey where $\mathrm{X}$-axis depicts the gender and $\mathrm{Y}$-axis depicts the number of respondents. $p$ value- 0.296 ( $p>0.05$ ) which shows that it is not significant. however more males(16\%) were aware of the wavelength of $\mathrm{Nd}$ :YAG used in disinfection of canals.

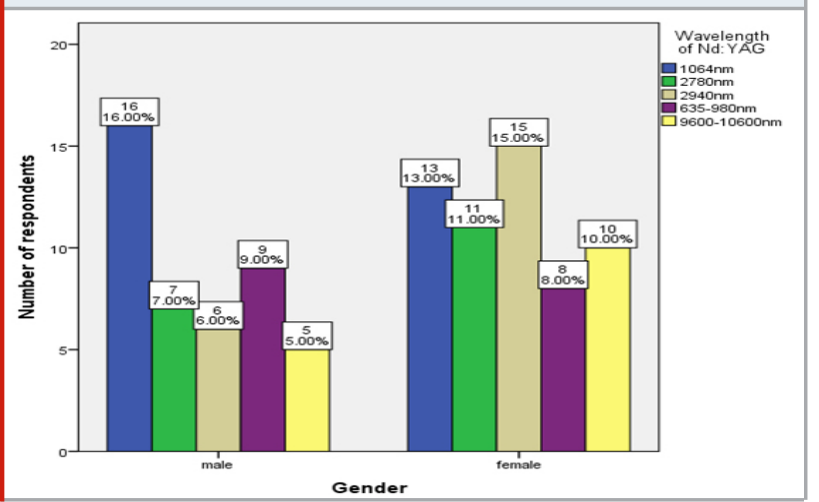

From figure 4, more females(18\%) were aware of the type of laser used in disinfection of canals. than males(10\%). From 5, more males(16\%) were aware of the wavelength of $\mathrm{Nd}$ :YAG used in disinfection of canals than females(13\%). From 6, more females (21\%) were aware of the wavelength of Er:YAG used in disinfection of canals than males(9\%). From 7, more females(22\%) were aware of the wavelength of Er,Cr:YSGG used in disinfection of canals than males(10\%). From 8, more females (25\%) were aware of the wavelength of diode used in disinfection of canals than males(17\%). From 9,females (19\%) were more aware of the wavelength of carbon dioxide used in disinfection of canals than males (8\%). The laser wavelengths described for cleaning and disinfecting the root canal system for erbium: yttrium aluminium garnet (Er:YAG) was found to be $2940 \mathrm{~nm}$, erbium, chromium: yttrium scandium gallium garnet (Er,Cr:YSGG) was found to be $2780 \mathrm{~nm}$; neodymium:yttrium aluminium garnet (Nd:YAG)was found to be $1064 \mathrm{~nm}$, diode was found to be 635 to $980 \mathrm{~nm}$,

Figure 6: This graph shows the association between gender and number of respondents for the survey where $\mathrm{X}$-axis depicts the gender and Y-axis depicts the number of respondents. $p$ value- $0.191(p>0.05)$ which shows that it is not significant. However more females (21\%) were aware of the wavelength of Er:YAG used in disinfection of canals.

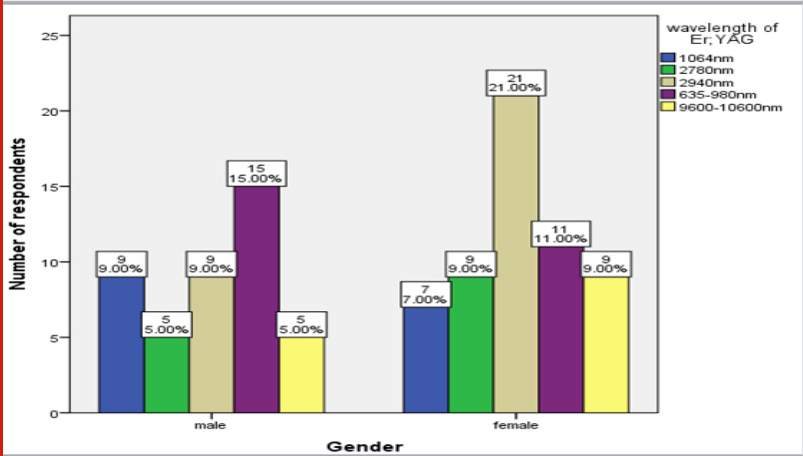

Figure 7: This graph shows the association between gender and number of respondents for the survey where $\mathrm{X}$-axis depicts the gender and $\mathrm{Y}$-axis depicts the number of respondents. $p$ value- $0.359(p>0.05)$ which shows that it is not significant. However more females(22\%) were aware of the wavelength of Er,Cr:YSGG used in disinfection of canals.

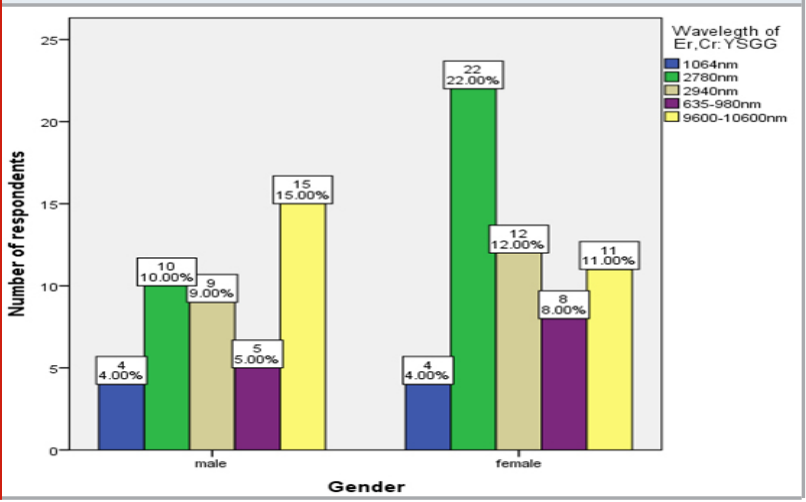

carbon dioxide (C02)was found to be 9600 and 10 $600 \mathrm{~nm}($ Asnaashari and Safavi, 2013).Nd:YAG have bactericidal effect up to $1 \mathrm{~mm}$ into the dentine. Moritz et al reported reduction of bacteria such as Enterococcus faecalis and Escherichia coli after Nd:YAG irradiation(Moritz et al., 1999). Gutknecht et al. also reported reduction in the number of intracanal Enterococcus faecalis using the Nd:YAG laser at $15 \mathrm{~Hz}$ and $100 \mathrm{~mJ}(G u t k n e c h t$ et al., 1996).Diode lasers have lower penetration depth into the dentine compared to 
Nd:YAG laser. Diode laser stimulates cell proliferation and shows inhibiting inflammatory enzymes. The bactericidal effect of Er,Cr:YSGG and Er:YAG is not as good as achieved with the Nd:YAG or diode laser. This kind of laser can penetrate only the areas closer to the canal.(Bhatia and Kohli, 2013).

Figure 8: This graph shows the association between gender and number of respondents for the survey where X-axis depicts the gender and $\mathrm{Y}$-axis depicts the number of respondents. $p$ value- $0.440(p>0.05)$ which shows that it is not significant. However more females (25\%) were aware of the wavelength of diode used in disinfection of canals.

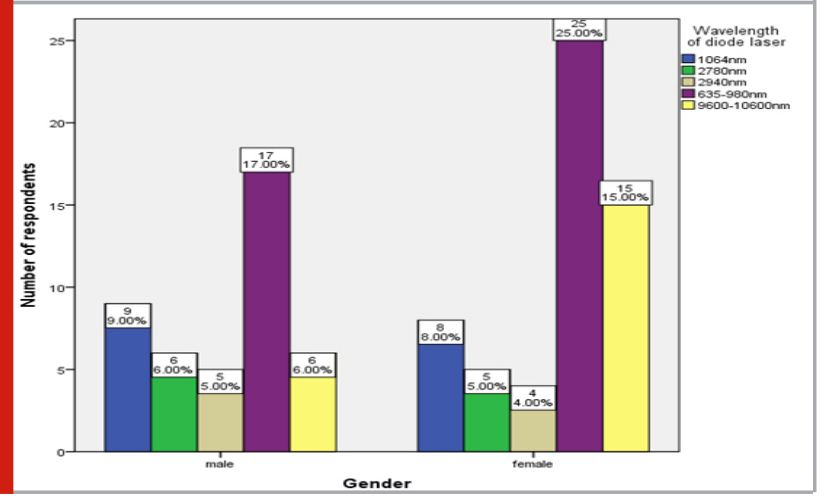

Figure 9: This graph shows the association between gender and number of respondents for the survey where $\mathrm{X}$-axis depicts the gender and $\mathrm{Y}$-axis depicts the number of respondents. $p$ value- $0.022(p<0.05)$ which shows that it is significant. It means the females (19\%) were more aware of the wavelength of carbon dioxide used in disinfection of canals than males (8\%).

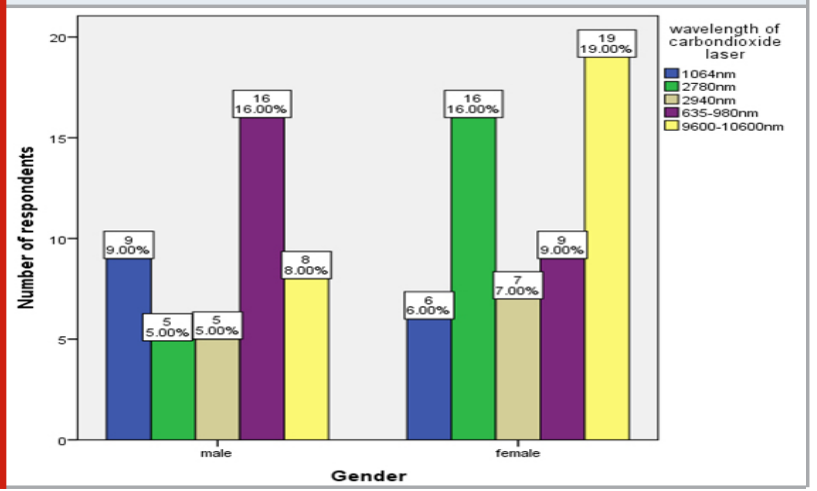

From figure 10, more females(38\%) were aware of the advantages of lasers used in disinfection of canals than males(27\%).Laser light can reach areas of canals where irrigating and disinfecting solutions cannot penetrate. Lasers can penetrate secondary canals and deep dentinal tubules and also can eliminate microorganisms(Asnaashari and Safavi, 2013). Various advantages of laser include improved root canal cleaning, disinfection efficacy, reduction of permeability, reduction of micro leakage and elimination of the need to use toxic solvents(Mathew et al., 2015).
Figure 10: This graph shows the association between gender and number of respondents for the survey where $\mathrm{X}$-axis depicts the gender and $\mathrm{Y}$-axis depicts the number of respondents. $p$ value- $0.848(p>0.05)$ which shows that it is not significant. However more females(38\%) were aware of the advantages of lasers used in disinfection of canals.

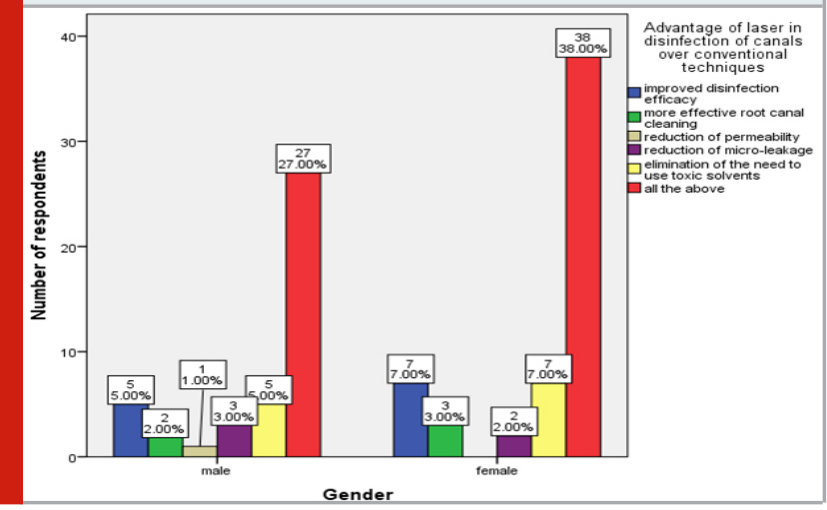

From figue 11, more females(32\%) were aware of the limitations of lasers used in disinfection of canals than males(25\%). Thermal damage of periradicular tissues through the open apical foramen may occur when using the erbium lasers at ablative settings(Hellingwerf, Hoff and Crielaard, 1996)Laser is dangerous in curved root canals because of the risk of creating ledges and perforations(Gutknecht et al., 2000; Jahan et al., 2006). Expense of the laser unit is often the limitations of laser usage.

Figure 11: This graph shows the association between gender and number of respondents for the survey where $\mathrm{X}$-axis depicts the gender and $\mathrm{Y}$-axis depicts the number of respondents. $p$ value- $0.639(p>0.05)$ which shows that it is not significant.However more females(32\%) were aware of the limitations of lasers used in disinfection of canals.

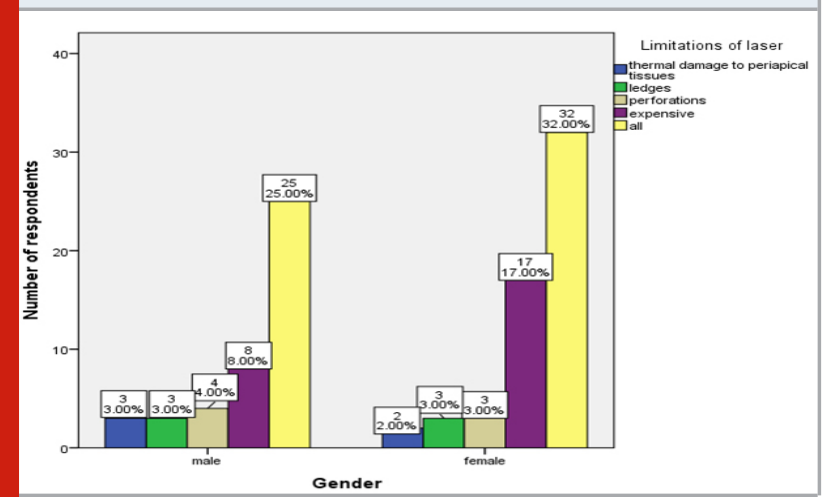

\section{CONCLUSION}

Within the limitations of the present study, it can be concluded that proper awareness should be created regarding laser use in disinfection of canals. From the present study, we can conclude that female participants are more aware on laser effect, laser advantages, limitations and on adjuvant role of laser with irrigants, 
wavelength of Er:YAG,Er,Cr:YSGG, Diode, carbon dioxide laser in disinfection of canals and males are more aware of the wavelength of Nd:YAG. But there is a need for an awareness among students regarding the current application of LASER for providing better treatment without any complications.

\section{ACKNOWLEDGEMENTS}

The authors would like to thank Saveetha Dental College and Hospitals for providing a platform

to conduct the study.

\section{Conflict of Interest: Nil}

\section{REFERENCES}

Asnaashari, M. and Safavi, N. (2013) 'Disinfection of Contaminated Canals by Different Laser Wavelengths, while Performing Root Canal Therapy', Journal of lasers in medical sciences, 4(1), pp. 8-16.

Azeem, R. A. and Sureshbabu, N. M. (2018) 'Clinical performance of direct versus indirect composite restorations in posterior teeth: A systematic review', Journal of conservative dentistry: JCD, 21(1), pp. 2-9. Bhatia, S. and Kohli, S. (2013) 'Lasers in root canal sterilization-a review', International journal of scientific study, 1(3). Available at: https://www.researchgate. net/profile/Shivani_Kohli/publication/259893869_ Lasers_in_Root_Canal_Sterilization_-A_Review/ links/Odeec52e74c2390bed000000/Lasers-in-RootCanal-Sterilization-A-Review.pdf.

Govindaraju, L., Neelakantan, P. and Gutmann, J. L. (2017) 'Effect of root canal irrigating solutions on the compressive strength of tricalcium silicate cements', Clinical oral investigations, 21(2), pp. 567-571.

Gutknecht, N. et al. (1996) 'Bactericidal effect of the $\mathrm{Nd}$ :YAG laser in in vitro root canals', Journal of clinical laser medicine \&t surgery, 14(2), pp. 77-80.

Gutknecht, N. et al. (2000) 'Diode laser radiation and its bactericidal effect in root canal wall dentin', Journal of clinical laser medicine \&t surgery, 18(2), pp. 57-60.

Gutknecht, N. (2008) 'Lasers in endodontics', J Laser Health Acad, 4(1), pp. 1-5.

Hellingwerf, K. J., Hoff, W. D. and Crielaard, W. (1996) 'Photobiology of microorganisms: how photosensors catch a photon to initialize signalling', Molecular microbiology, 21(4), pp. 683-693.

Jahan, K. M. R. et al. (2006) 'An assessment following root canal preparation by Er,Cr:YSGG laser irradiation in straight and curved roots, in vitro', Lasers in Medical Science, pp. 229-234. doi: 10.1007/s10103-0060401-2.

Jain, P. and Ranjan, M. (2014) 'Role of herbs in root canal irrigation-A review', IOSR Journal of Pharmacy and Biological Sciences, 9(2), pp. 06-10.
Janani, K. and Sandhya, R. (2019) 'A survey on skills for cone beam computed tomography interpretation among endodontists for endodontic treatment procedure', Indian journal of dental research: official publication of Indian Society for Dental Research, 30(6), pp. 834-838.

Jenarthanan, S. and Subbarao, C. (2018) 'Comparative evaluation of the efficacy of diclofenac sodium administered using different delivery routes in the management of endodontic pain: A randomized controlled clinical trial', Journal of conservative dentistry: JCD, 21(3), pp. 297-301.

Juri囚, I. B. and Ani囚, I. (2014) 'The Use of Lasers in Disinfection and Cleanliness of Root Canals: a Review', Acta stomatologica Croatica, 48(1), pp. 6-15.

Kaiwar, A. et al. (2013) 'The efficiency of root canal disinfection using a diode laser: in vitro study', Indian journal of dental research: official publication of Indian Society for Dental Research, 24(1), pp. 14-18.

Khandelwal, A. and Palanivelu, A. (2019) 'Correlation Between Dental Caries And Salivary Albumin In Adult Population In Chennai: An In Vivo Study', Brazilian Dental Science, 22(2), pp. 228-233.

Kreisler, M. et al. (2003) 'Efficacy of $\mathrm{NaOCl} / \mathrm{H} 2 \mathrm{O} 2$ irrigation and GaAlAs laser in decontamination of root canals in vitro', Lasers in surgery and medicine, 32(3), pp. 189-196.

Malli Sureshbabu, N. et al. (2019) 'Concentrated Growth Factors as an Ingenious Biomaterial in Regeneration of Bony Defects after Periapical Surgery: A Report of Two Cases', Case reports in dentistry, 2019, p. 7046203.

Manohar, M. P. and Sharma, S. (2018) 'A survey of the knowledge, attitude, and awareness about the principal choice of intracanal medicaments among the general dental practitioners and nonendodontic specialists', Indian journal of dental research: official publication of Indian Society for Dental Research, 29(6), pp. 716-720.

Mathew, A. et al. (2015) 'An in vivo study on comparison of disinfection of root canal with chemical disinfectants and disinfectant-diode laser-photodynamic treatment combined system', Journal of Dental Lasers. Medknow Publications, 9(1), p. 2.

Meire, M. and De Moor, R. (2007) 'Lasers in endodontics: laser disinfection, an added value?', Endodontic Practice Today, 1(3). Available at: http://search.ebscohost.com/ login.aspx? direct=truectprofile=ehostetscope=sitectaut htype $=$ crawlerCtjrnl $=17532809 \& A N=37379040 \& \mathrm{th}=\mathrm{zc}$ MNZPloR0URFohgZlzCtFxXhq8P5MrC8MpqK\%2FwC KIHfqncMszjyWHVNHBmAyP1JGRtkQBYonhzUF12w c4tPgw\%3D\%3Detcrl=c.

Moritz, A. et al. (1999) 'The bactericidal effect of $\mathrm{Nd}$ :YAG, Ho:YAG, and Er:YAG laser irradiation in the 
root canal: an in vitro comparison', Journal of clinical laser medicine \&t surgery, 17(4), pp. 161-164.

Nandakumar, M. and Nasim, I. (2018) 'Comparative evaluation of grape seed and cranberry extracts in preventing enamel erosion: An optical emission spectrometric analysis', Journal of conservative dentistry: JCD, 21(5), pp. 516-520.

Narayanan, L. L. and Vaishnavi, C. (2010) 'Endodontic microbiology', Journal of conservative dentistry: JCD, 13(4), pp. 233-239.

Perin, F. M. et al. (2004) 'Evaluation of the antimicrobial effect of Er:YAG laser irradiation versus 1\% sodium hypochlorite irrigation for root canal disinfection', Australian endodontic journal: the journal of the Australian Society of Endodontology Inc, 30(1), pp. 20-22.

Plotino, G. et al. (2016) 'New Technologies to Improve Root Canal Disinfection', Brazilian dental journal, 27(1), pp. 3-8.

Poorni, S., Srinivasan, M. R. and Nivedhitha, M. S. (2019) 'Probiotic strains in caries prevention: A systematic review', Journal of conservative dentistry: JCD, 22(2), pp. 123-128.

Preethee, T. et al. (2012) 'Bactericidal effect of the 908 $\mathrm{nm}$ diode laser on Enterococcus faecalis in infected root canals', Journal of conservative dentistry: JCD, 15(1), pp. 46-50.

Rajakeerthi, R. and Ms, N. (2019) 'Natural Product as the Storage medium for an avulsed tooth - A Systematic Review', Cumhuriyet Dental Journal, 22(2), pp. 249256.

Rajendran, R. et al. (2019) 'Comparative Evaluation of Remineralizing Potential of a Paste Containing Bioactive Glass and a Topical Cream Containing Casein Phosphopeptide-Amorphous Calcium Phosphate: An in
Vitro Study', Pesquisa brasileira em odontopediatria e clinica integrada, 19(1), pp. 1-10.

Ramarao, S. and Sathyanarayanan, U. (2019) 'CRA Grid - A preliminary development and calibration of a paper-based objectivization of caries risk assessment in undergraduate dental education', Journal of conservative dentistry: JCD, 22(2), pp. 185-190.

Sheik, R. and Ranjan, M. (no date) 'Assessment of Knowledge about the Effects of Root Canal Irrigants among Dental Students'. Available at: http://www.ijsdr. org/papers/IJSDR2002028.pdf.

Siddique, R. et al. (2019) 'Qualitative and quantitative analysis of precipitate formation following interaction of chlorhexidine with sodium hypochlorite, neem, and tulsi', Journal of conservative dentistry: JCD, 22(1), pp. 40-47.

Siddique, R. et al. (2020) 'Comparison of antibacterial effectiveness of three rotary file system with different geometry in infected root canals before and after instrumentation-a double-blinded randomized controlled clinical trial', BDJ open, 6, p. 8.

Siddique, R. and Nivedhitha, M. S. (2019) 'Effectiveness of rotary and reciprocating systems on microbial reduction: A systematic review', Journal of conservative dentistry: JCD, 22(2), pp. 114-122.

Siddique, R., Nivedhitha, M. S. and Jacob, B. (2019) 'Quantitative analysis for detection of toxic elements in various irrigants, their combination (precipitate), and para-chloroaniline: An inductively coupled plasma mass spectrometry study', Journal of conservative dentistry: JCD, 22(4), pp. 344-350.

Teja, K. V., Ramesh, S. and Priya, V. (2018) 'Regulation of matrix metalloproteinase-3 gene expression in inflammation: A molecular study', Journal of conservative dentistry: JCD, 21(6), pp. 592-596. 